\title{
The Unreality of Evil
}

\author{
W. J. Mander ${ }^{1}$
}

Published online: 23 March 2017

(C) The Author(s) 2017. This article is published with open access at Springerlink.com

\begin{abstract}
The simplest response to the problem of evil is to deny that there exists any evil, but that answer is usually dismissed as obviously unacceptable. This paper takes issue with that assessment and argues that it is an answer deserving of serious consideration. After rejecting four manifestly unacceptable formulations, two further conceptions are identified - the 'higher standard' and 'wider perspective' answerswhich merit closer attention. The remainder of the paper considers and responds to four main objections to the theory: that it runs contrary to our experience, that it is selfdefeating, that it makes a nonsense of worship and that it would undermine moral action.
\end{abstract}

Keywords Evil · Unreal · Illusion · Holism · 'Higher standard' · Wider perspective'

Including in its scope natural as well as moral defect, the 'evil' which is the subject of the traditional problem of evil must be understood as any sort of negative contribution to the overall axiological worth of reality: anything which is less than perfect, either individually or collectively. The simplest defence against this challenge is just to deny that there exists any such evil. As well as being the simplest, this is the least popular of all answers and the suggestion is usually given very short shrift indeed: typically dismissed in a sentence or so as obviously unacceptable. In this paper, I take issue with that judgement and argue that this much-despised answer is more tenable than is usually thought. The key question is whether or not it is possible to hold to the unreality of evil despite all of the apparent facts to the contrary. The majority of people have thought not, but I aim to show that, at the very least, this conclusion needs to be a considered one, rather than something which may simply be assumed from the start.

The comparative issue of whether the unreality-of-evil approach should be preferred to other more familiar alternatives is far too large to be tackled here, and so I restrict myself to the more modest and hypothetical task of attempting to persuade readers of its

W. J. Mander

william.mander@hmc.ox.ac.uk

1 Harris Manchester College, Oxford OX1 3TD, UK 
basic viability, resting for the moment its positive case on the fact that its basic motivation is plausible enough. Given the nature of God, it is reasonable to expect that the world that he created is one which is both wholly good and could not be bettered - that it contains nothing in any way contrary to his will — while it can also be argued that this is the only philosophical response that holds firmly on to the omniscience, omnipotence and goodness of God without any qualification whatsoever. The equally large issue of whether or not this answer is compatible with any specific religion must also be left aside for another day.

\section{I}

It must be allowed from the outset that a number of versions of the unreality-of-evil answer are indeed very poor, and so, I begin by simply enumerating and discarding them. First of all, it might be urged that evil is unreal because reality in itself is axiologically neutral. It exists and it has a nature, but these are descriptive facts, and wholly distinct from values which must be thought of as nothing more than our own 'subjective' responses to them: interpretations or projections that we 'add' to the bare naturalistic facts. Such value anti-realism will hardly want for supporters, but it is simply beside the point, for the problematic we are considering only begins once we assume the reality of divine goodness. We are interested here in approaches which take a different attitude towards the good than they do towards what is bad, approaches which are realist about the one but dismissive of the other, whereas the naturalistic point of view is sceptical about both. ${ }^{1}$

Secondly, it might be argued that evil is unreal because it is a privation, merely the absence of a good which ought to be there, as for example, blindness is the absence of sight or disease is the absence of health (Calder 2007). This is a wholly orthodox theological view, of course, and I mention it only to dismiss it as irrelevant. It is important to distinguish between existence and reality. That which is absent may not exist, but absences themselves are all too real. On the classical theistic view, the occurrence of evil is certainly a fact, albeit a negative one, while the alternative view which we are considering in this paper holds precisely that there is no such fact. To claim that evil is unreal is to hold that synthetic propositions about what is or is not evil are all necessarily false, in the same way that an atheist holds that all factual propositions about God are false. ${ }^{2}$

Perhaps the best known source for the view that evil is unreal is the position advanced by Christian Science that it is an illusion caused by, or otherwise bound up with, the mistaken belief in material reality. Mary Baker Eddy urged 'the nothingness and unreality of evil', maintaining that it 'has no reality. It is neither person, place, nor thing, but is simply a belief, an illusion of material sense.' All we need do is to recognise this point, and evil would henceforth vanish. 'If sin, sickness, and death were understood as nothingness, they would disappear.' (Eddy 1934 p.205, p.71,

\footnotetext{
${ }^{1}$ It is thus mistaken to criticise the 'unreality of evil thesis' on the grounds that that would entail also the unreality of goodness. (Davies 2006, p.143) If this seems puzzling we might think of the comparable case of 'existence'- which can be affirmed but never truly denied of any individual.

2 The atheist might add that the true proposition 'There is no God' is not, of course, a proposition about God.
} 
p.480) Not many have found it plausible to claim that matter is unreal, but perhaps the easiest way to dismiss this answer is simply to point out that many evils (such as the tragedy of having one's heart broken, or of losing one's faith) are entirely mental or spiritual in nature.

Fourthly, we can consider the view that evil is an illusion brought about by the unfortunate habit of desire: which (it is said) is simply a matter of not getting what we want. Once we free ourselves from desire, it is argued, we free ourselves from all suffering and see that the world contains nothing but goodness. Desire is a condition that distorts our axiological vision. Without entering into complex doctrinal debates, I think that such a view might fairly be associated with Buddhism. It would take us too far afield fully to discuss this theory, and so we may simply note that while it is plausible to think that all suffering is accompanied by frustrated desire - not least the desire that it should cease - that fact is very far from demonstrating that all suffering is caused by frustrated desire.

\section{II}

None of the four views above offer a plausible account of the unreality of evil. However, there are two further conceptions - which we may dub the 'higher standard' and 'wider perspective' answers - which merit closer attention. Although natural allies and often conflated together, the two positions are different, in that a person might hold one but not the other, and in the following two sections I consider them in turn.

As adults may have more advanced or more nuanced conceptions of matters than children, so it might be suggested that God's understanding of good and evil is more profound, more sophisticated, or more subtle, than that of human beings. Intellectually and morally outstripping our own by miles, the divine conception of what it means for something to be 'good' or 'bad' may be one against which any other sense of the distinction appears cramped, simplistic and unimaginative. More specifically, it may be the case that sometimes what seems evil to us, from his more enlightened understanding, God can recognise as in fact good. This kind of answer differs from that of the Christian Scientist or the Buddhist in that the illusion of evil is traced, not to anything specific which we might seek to overcome (such as a belief in material reality, or the presence of desire) but rather to an entirely general feature of our cognition-its inherent finitude - about which we can do nothing. The suggestion that God might work with a higher concept of good and evil is not new. In modern times it is perhaps most famously associated with Henry Mansel. But as Mansel well knew, the view was already an ancient one, and prior to that it is most commonly presented as the doctrine that religious language is 'analogical' - that terms applied to God may not be taken as having exactly the same sense they do when applied to creation. ${ }^{3}$

Different ways may be found of expressing this contrast between human and divine conception - some stressing how limited and thin finite comprehension must be, others

\footnotetext{
3 'It is no disparagement of the value and authority of the Moral Reason in its regulative capacity, within its proper sphere of human action, if we refuse to exalt it to the measure and standard of the Absolute and Infinite Goodness of God.' (Mansel 1867, p.160) In support of this view Mansel quotes extensively from a variety of authorities, both ancient and modern. (ibid pp.xx-xliv)
} 
maintaining that partiality must lead to distortion or confusion-but however precisely it is taken, the suggestion that God operates with a higher standard of value than we can grasp implies that it is wrong for us to judge him by our own standards. At this point there arises a certain potential for confusion. Presentations of this argument often slide from 'wrong' in the sense of incorrect or mistaken to 'wrong' in the sense of impertinent and presumptuous, turning into complaints about arrogant pride, or issuing forth calls for humble acceptance. Whether they have any foundation or not, these further extensions should all be put to one side, for is unhelpful to confuse the conceptual issue with the moral one. ${ }^{4}$

Under what conditions may we judge that one concept is a higher (as opposed to simply a different) version or expression of some other concept? There are two distinct ways (not necessarily incompatible) in which this relationship might be demonstrated to hold. The first method would be to show how the higher concept yields up the lower one as a limiting case of itself. For example, Special Relativity is a higher theory than Classical Mechanics because the claim that simultaneity does not vary according to one's frame of reference holds well enough in Special Relativity also, so long as one limits one's consideration to velocities well below that of the speed of light. If we suppose Newton's principles to be absolutely universal laws, they must be dismissed as incorrect, but certainly for the most part within our local experience they hold good, and Einstein's theory moreover explains why they do so. Similarly we might suppose that God's concept of goodness is higher than our own because for the most part it agrees with ours - that is to say, God does not normally endorse what we think of as reprehensible - even if in certain unusual or special cases it yields a result which is directly contrary to our own understanding. This way of explaining how God's goodness might be 'higher' than ours, of how our conception might be a limiting case of his, is theoretically sound. But it must be confessed that it is of only modest heuristic use to us because to really appreciate what it means to call one concept a limited instance of another, you need access to both concepts. Yet on the scheme we are considering here, the second concept — God's — is precisely what lies beyond our reach.

For this reason it is helpful to explore a second model for understanding how one concept might be a higher version of another. This explanatory model appeals to the common enough phenomena of conceptual development or evolution, whereby (either in the life of an individual or of a species) an initially simple or superficial concept is progressively deepened and enriched, passing beyond and even correcting its starting point. We may consider the following illustrative examples. (i) A straightforward mind might begin by supposing that all truth is literal and hence that metaphorical statements are falsehoods. But as we let their poetical meaning sink in, we may advance to a richer understanding of truth in which at least some metaphors - 'All the world's a stage', 'time is a thief', 'the past is another country' — come to seem not false, but importantly true. (ii) If we begin with a traditional understanding of art, certain modern or avantgarde creations may seem to us to be not art at all. But if someone explains the ideas behind them, and we come to see how they result from extensions to ways of thinking of the same basic kind as those which inspire more conventional pieces, then our conception may be refined and deepened and we may admit that what before seemed so

\footnotetext{
${ }^{4}$ Kane (1975, p.54) helpfully distinguishes here between what he terms 'the unintelligibility thesis' and the 'impropriety thesis'.
} 
obviously not so, is indeed art. We might even come to wonder if the chocolate-box kitsch that we once thought so clearly the genuine article is really so 'artistic' after all. (iii) Ethical examples also may be found. Moral feeling begins with the thought that we should have concern for those nearest to us, with whom we share a common lot. Yet once we ask 'Who is my neighbour?' we start along a path of conceptual evolution which gradually leads us to extend the sphere of care to those who once fell outside it. Again, a natural point of origin for thinking about right and wrong is the idea of 'rule' or 'law'. But as we reflect upon that notion, we come to see a distinction between the letter and the spirit of the law, and consequently to recognise that an act can be technically legal and yet at the same time profoundly wrong.

The locus classicus for the claim that ideas have an inherent tendency to evolve and develop is Hegel, but even without defending a fully-fledged dialectical philosophy, something of this sort might be thought plausible with respect to moral concepts. It is reasonable to think that there has been conceptual evolution in moral thinking - that modern ethical ideas are more advanced than those of our ancestors - but the case for saying that we ought to project that process of development into the future is not simply inductive. Rather, it stems from the fundamentally self-critical nature of ethical judgement. Charles Taylor draws a distinction between agents who practise 'weak evaluation', comparing different options by reference to a given set of desires, and those who engage in 'strong evaluation', extending the realm of their assessments to include selfreflexive judgement about the very desirability of having the desires they do. (Taylor 1976) It is the latter characteristic of moral judgement that propels it ever forward, and which makes it reasonable to suppose that tracing out a line of progressively deeper understanding of goodness from our own up to God's - we could perhaps imagine angels as an intermediary mid-point - would display precisely such a scheme of conceptual growth. It is in this sense that we may suppose that God operates with higher or more advanced moral concepts than our own.

\section{III}

According to the second of the two more plausible ways of denying the reality of evil, the apparent existence of evil is an illusion consequent upon our failure to grasp the full picture of existence itself. It is a sign that our perspective is not adequate to the whole universe: that is to say, that ours is an incomplete view of things, which fails either to register the proper context of events (contextualism) or to appreciate the way in which everything fits together (holism). To a viewpoint able to take in all things and place them in their proper relationships - the 'God's eye view' - everything would be understood to be exactly as it ought to be. There would be no evil.

One reason why this second sort of answer to the problem of evil has received as little attention as it has is that it runs counter to the prevailing assumption of reductive analysis which generally holds sway: the assumption that things are best understood by breaking them down into their elements. But even if such decomposition is a plausible approach in metaphysics (which might be challenged) it is much less so with respect to value. Beauty, for example, is highly contextual and integrative. The object that looks perfect in one location may be an eyesore in another, while a work of art is more than just a set of individually artistic components. And comparable illustrations may be 
proposed for moral evaluation also. That moral judgements vary from context to context has recently been defended under the banner of moral particularism, (Dancy 2004) while value holism is at least part of what is meant by the 'unity of the virtues' the thesis that distinct virtues cannot be held in isolation but only together in concert. For example, we may suppose that it is the kindness, honesty and flexibility of what we do in a given situation which make that the right way to behave, or the pride, fear and conscientiousness of our action in some other case that make it wrong. But if these values combine to determine the final ethical significance of the act, it is not by being added together like numbers in a column or ingredients for a cake. Rather each characteristic gains its precise significance and value through the way in which it appears in context with the others. ${ }^{5}$

It should be stressed that the examples given above are heuristic or illustrative only, put forward with the aim of showing that the suggestion of 'a more complete vision' is not one not wholly beyond our grasp. They advise us only of a solution to the problem of evil in the universe that would work 'something like this'. It is worth focusing on the reason why such heuristic illustration is all that can be offered here. The problem is that we do not have, nor can we easily imagine ourselves acquiring, that greater perspective enjoyed by God. God judges the 'whole universe' 'as a whole' but it is impossible for us to know fully what that would amount to, and indeed hard enough for us for us to get much more than a rudimentary handle on its meaning.

The possible roots of this cognitive limitation bear further examination. Specifically, there are two ways in which our finite grasp may be defective. In the first place, in our finitude, we may fail to take in 'the whole universe.' The idea here is a realist one: that there is just a very great deal more to the universe than we know or ever imagine, and our view may be defective in so far as it simply misses out certain properties or phenomena. Perhaps, rather as physicists need to posit 'dark matter' to explain how galaxies rotate at the speeds they do without tearing themselves apart, or as psychologists need to posit 'unconscious desires' to explain otherwise mysterious human actions, so it may be that the universe contains a hidden axiological dimension - an 'ideal accompaniment' for each seeming evil—which alters its final evaluative score.

Even if one is aware of all relevant materials or components, one may just fail to put them together appropriately, as (for example) when all that I can see is a string of letters I am failing to grasp the word which together they make up. In similar fashion, the second sort of defect from which finite creatures may suffer is an inability to understand, as God does, how everything fits together to form one whole. God grasps 'the universe as a whole' but such an act of integration may be beyond us. The imaginative deficient involved here makes it hard even to clearly understand the proposal, but if the nature of the case rules out our giving any actual examples, it may nonetheless be possible to offer a number of suggestive prompts. Here are three such hints. (i) As creatures with a determinate spatio-temporal location, we encounter the universe as 'spread out' across space and time and interpret possibilities of combination accordingly. But is that how God sees things? It is commonly suggested that God's view is neither spatially nor temporally indexed - that in some fashion all places are 'here' to him and all times 'now'. Yet if that is so, it may well affect the ways in which apparent

\footnotetext{
${ }^{5}$ Analytic philosophy's engagement with the holism of value has largely centred around Moore's notion of 'organic unities' (1903, pp.27-36). For further discussion of the topic see (Mander 2016, ch.18)
} 
good and evil combine together. (ii) It may also be that to a God who lives 'within' as much as 'without' - who knows from the inside the feelings of all individual creatures - that the differences between different individual minds count for less, or at least count differently, than they do for us. The way in which different thoughts and feelings combine together to form a pleasurable experience, or the way in which various experiences combine together to form a successful life may be better models to bear in mind here than a scheme for filling as many cups as possible each as full as possible. (iii) Perhaps as a result of our spatio-temporal individuation we are creatures for whom the individuality of being strikes with more force that its universality. But does God see things the same way? Suppose I am filled with compassion for individual creatures (say, foxes) and, saving even the weak and sick ones that come my way, I end up lowering the genetic strength of the local population. Someone might accuse me of failing to see the big picture. 'It may seem cruel to let nature take its course,' I will be told, 'but what matters is to help the fox, not individual foxes'. Is God's concern focused on individuals or on universals, or does it perhaps show no bias either way, somehow bringing these two interests together in an even-handed fashion?

It may be thought that the sort of 'wider perspective' answer outlined above is no different from that of standard sceptical theism, but while there are certainly similarities with that position, there is one very important difference which must not be overlooked. Sceptical theism maintains that we, by cause of our limited perspective, may be ignorant of the reasons which justify apparently gratuitous evils: their presence in fact rendering the world better than it would otherwise have been. Thus accepting the reality of evil, sceptical theism is a form of 'greater good response' to the problem of evil. However, the notion of a 'summum bonum' is equivocal, and in this particular context we must distinguish between perfection as 'the best there can be' and perfection as 'that which is wholly without defect.' If the goodness of God itself meets the both standards, then can it really be that his creation is able only to attain the first? By contrast with sceptical theism, the view that we are outlining here appeals to a wider perspective to deny the very reality of evil, not just its apparent lack of outweighing and justifying reason. The issue hinges on that of the fundamental difference between parts and wholes. While to the greater good theorist the whole value is made up of distinct part values - some bad, but accompanied by other outweighing goods - to the value holist the seeming worth of the parts individually (negative or positive) are not genuinely autonomous values at all, but merely abstractions from the only authentic value there is, that of the whole. One-sided aspects or features pulled out from a larger context and treated in isolation, part values are distorted fragments of a greater whole to which they contribute but do not apply - at least not without major qualification or development. This is why re-instituting their context can completely reverse our initial and decontextualised assessment of their worth (as we ourselves sometimes experience in limited fashion when a subsequent increase in our understanding shifts our original valuations.) This difference needs to be born clearly in mind with respect to the possibility that we canvassed above, of 'extra' unknown features of the universe which added to an apparent evil may serve to change its value. The extra that is appealed to here is not some further value part - any more (for example) than is the form that is 'added' to any given matter.

Value holism is not a very widely accepted position, and there will never be any shortage of people inclined to challenge suggested examples, proposing instead that 
they are really greater good answers. Indeed, rather in the way that altruistic motives can always be written out to maintain an egoistic presupposition, it may even be that it is always possible to offer re-construals of holistic answers as greater good ones. But whether, this ought always to be done is quite another matter, for an unreality-of-evil answer has at least prima facie advantage over one that compromises the scope of divine omnipotence to bring about what is best, and taints divine beneficence with a variety of grubby utilitarian trade-offs.

One last point remains. Before we leave exposition to head into criticism, it may be useful to say a few words about the relation between the 'higher standard' answer and 'wider perspective' ways of understanding the unreality of evil. While mutually compatible, they are separate. A creature might have superior moral judgement because although it sees no wider than we do, it nonetheless works with a higher standard. Or again, the superiority of its judgement might lie solely in the breadth of its vision across which it uses exactly the same standard as we do. It must be allowed that not all scholars have noted the difference between these two answers, and the likely reason for this is that they fit rather neatly together. That is to say, it may plausibly be thought that God both uses a higher standard of value and sees the world more completely.

\section{IV}

By this stage the reader may well feel that we have already spent far too long expounding a theory which is simply untenable, and so I press on to counter some criticisms of the unreality-of-evil thesis, for it is (I maintain) no mere 'theoretical possibility' but a serious and live option for responding to the sufferings of life. In the end they reduce down to four main challenges. First of all, the most striking objection to the claim that there is no evil must be, of course, the sheer and utter implausibility of the suggestion. We have only to pay attention to the national news, or inquire more closely into the lives of those around us, for the pain and suffering that everywhere abounds to begin to overwhelm us. How can anyone faced with such terrible things possibly claim that evil does not exist?

In response to this challenge it is necessary to distinguish between appearance and reality, between what looks bad and what genuinely is bad. It would be crazy to deny that there appears to be a very great deal of evil. But as a stick appears bent in water although it is not really so, it may equally be the case that things seem to be very bad even though a full and accurate picture would not describe them in that way.

It is worth dwelling on this response, for there is no disputing that it is very counterintuitive. Part of the resistance here lies in an underlying thought that illusion or appearance is avoidable. The stick may look bent, but we have only to remove it from the water to come to see that it is really straight. Yet there is no such correction available that will allow us to see past the illusion of evil. We have no chance of reaching any vantage point from which the deception is uncovered. This is true enough, but it is no part of the very notion of an appearance that it can be circumvented by those who suffer it. Many misapprehensions are unavoidable, and this may be the case with the illusion of evil as well. There can be no denial that things really do seem evil, but it may be that this perception holds us firmly and inescapably in its grip, such that we are without any way to stop them seeming awful: even if we know at some deeper level or 
in some other fashion that they are not really so. But to know this can offer a real consolation, in the sense that I can believe something even if I cannot bring myself to see or feel it.

The intuitive opposition to this suggestion feeds off a further hidden assumption that whatever appears to be evil, thereby, just is evil — we see no room here for a distinction between appearance and reality. But we must distinguish between phenomenology and ethical evaluation. For it is no part of this view to deny the experience of pain, or sorrow, or disease, or any other calamity. No issue is taken with any facts of phenomenology or of science - only with their ethical evaluation. To say that things feel painful is not the same as to say they are bad. Pain is defined by its phenomenology; whatever feels painful just is pain. If I think I am miserable, then I am miserable. (Kripkie 1980, pp.151-2; Geach 1972, p.305) But value is not defined phenomenologically. There is no feeling of goodness or badness. That is always a judgement. And as such it can be mistaken. Were good and evil qualities we could directly perceive, the theory that evil is an illusion would be absolutely untenable. But they are not; they are further inferences from or interpretations of what we sense., ${ }^{6} 7$

\section{IV}

A second serious objection to the thesis that evil is unreal was put forward by the early twentieth century idealist, McTaggart, who complained that the thesis is self-contradictory. If evil is unreal, then surely the misperception or illusion that hides from us the genuine and unspoiled goodness of all things must itself be regarded as an evil: in which case evil is real, after all. It would seem that the thesis of the unreality of evil implies its own falsity. (McTaggart 1906, pp.209-10; 1921-7, volume II, pp.442-3; Davies 2006, p.143)

It need not be denied that some who have urged that evil is unreal have indeed fallen into this trap. For instance, Christian Science teaches that since evil is but an illusion we must learn to see through this deception. (Disease and pain, for example, have no reality and instead of going to a doctor or taking medicine it is our duty rather to pray for clearer vision.) But, of course, to suggest in this fashion that we ought to avoid or rise above our misapprehension is to imply that such delusory appearance itself is an evil, and hence that evil is after all real.

The most promising way in which to respond to McTaggart's challenge is to hold that while the appearance of evil may itself be a second and further evil, there is no reason to suppose this new evil any less illusory and apparent than all the others, for the principle that we are considering is one that has the property of applying to its own, as well as to other evils. To make a comparison, the ruling that all decisions are final

\footnotetext{
${ }^{6}$ However natural or obvious it may seem to us, hedonism (the theory that pleasure is intrinsically good and pain intrinsically bad) is something that must be demonstrated, for there is no intrinsic incoherence in separating the sensation from its typical evaluation. We might suppose, for example, that there is nothing good at all about the pleasure that a sadistic torturer gets from hurting his victim.

${ }^{7}$ It might be thought odd to say that evil is an illusion or appearance if it is not any sort of perception or intuition, but as well as misleading perceptual appearances (straight sticks that look bent), there can also be misleading conceptual appearances (a company that looks corrupt but is not really, shoes that look expensive but really were cheap).
} 
introduces a new decision (let us suppose it is the pronouncement of an appeal court asked to adjudicate on some matter) but there is no reason to suppose that this decision is any less final than the others, for the ruling has the property of applying to itself as well as to other decisions.

In his discussion of the matter, McTaggart anticipates and rejects this reply, on the grounds that it would generate a vicious infinite regress. He argues that if we downgrade the apparent evil of evil appearing to exist as but one more illusion, this further appearance must itself be regarded as a something genuinely evil, a third evil. Of course, we might respond that this third evil too is only an appearance, but by this stage it is clear that we have embarked upon an alternating regress that may be extended back without end.

However, McTaggart's attempt to block this method of dealing with his objection is unsuccessful, for it begs the question. He portrays the situation as one in which every claim that evil is apparent has the unfortunate consequence of generating a real evil - as a sort of by-product - which if we chose to dismiss it too as apparent, will spin-off yet another real evil, and so on... (One might imagine here a criminal who attempts to erase evidence, only to leave behind new evidence - evidence of removing evidence which must itself be erased, and so on ...) But the response that McTaggart hopes to criticise is one that works precisely by rejecting his opening move here. No doubt it must seem to us regrettable that a perfect world should appear to be flawed, but this further flaw is just one more appearance, not any kind of stubborn refutation that keeps escaping our repeated attempts to bring it into line.

It might be responded that while this may be so, we are still adding more and more new evils each time we apply the unreality of evil thesis: the evil of apparent evil, the evil of the apparent (evil of apparent evil), the evil of the apparent (evil of the apparent (evil of apparent evil)), and so on... But even if our reasoning produces a never ending sequence of evils, it is far from clear why we need to regard this as anything more than a benign regress of implications rather than a vicious one of self-refutations. For really it seems no more worrying than the regress which results from assuming that it is good to aim at what is good (and hence that we should aim to aim at what is good, etc.) or than the regress which ensures from thinking that if 'p' then 'it is true that p' (and hence that 'it is true that it is true that p.' etc.).

\section{VI}

The notion that God's moral vision of the universe might so differ from ours that the things we call evil may appear good to him was criticised by J.S. Mill. His objection is as famous as it is eloquent and it bears repeating. Against Mansel's suggestion that divine goodness is a very different thing from human goodness he complains:

If in ascribing goodness to God I do not mean what I mean by goodness; if I do not mean the goodness of which I have some knowledge, but an incomprehensible attribute of an incomprehensible substance, which for aught I know may be a totally different quality from that which I love and venerate - and even must, if Mr. Mansel is to be believed, be in some important particulars opposed to this-what do I mean by calling it goodness? and what reason have I for 
venerating it? .... To say that God's goodness may be different in kind from man's goodness, what is it but saying, with a slight change of phraseology, that God may possibly not be good?... when I am told that I must believe this, and at the same time call this being by the names which express and affirm the highest human morality, I say in plain terms that I will not. Whatever power such a being may have over me, there is one thing which he shall not do: he shall not compel me to worship him. I will call no being good, who is not what I mean when I apply that epithet to my fellow-creatures; and if such a being can sentence me to hell for not so calling him, to hell I will go. (J.S.Mill 1878, pp. 128-9). ${ }^{8}$

If we look into the matter, we can see two different strands of thinking here. In the first place we find an opposition to the supposed 'higher good' itself. It is unknown and could be just anything, goes Mill's complaint - even the complete opposite of what we mean by 'good'. In the second place we find a preference for the more familiar 'lower' sense of good. Whatever this supposed 'higher good' may be, goes the thought, it is nothing to us, for our concepts operate at the lower level. We want a God concerned with good and evil as we understand them. Otherwise why would we worship him? The points may be dealt with separately.

It must be allowed that Mansel did invite the first of Mill's complaints by virtue of a careless formulation of his view - which he later withdrew - but more fundamentally the objection is simply based on a misunderstanding. The criticism is that if we commend the universe from the 'higher point of view' then it is not what we ordinarily mean by 'good' - indeed, perhaps it is even what we mean by 'evil'. In response to this we may say that it is a poor understanding of meaning that gives us only a choice between perfect synonymy and complete difference of meaning. Clearly, the divine concept is not just a totally separate and distinct notion: not a straightforward equivocation, like the two different meanings of the word 'bank' or 'bat'. For then there would be no point in calling it a 'higher concept' or saying that it is a concept 'of goodness'. Rather, in the fashion we outlined above, the higher sense needs to be understood as a 'successor sense' or 'development out of' of our current meaning.

In order to defend such a line it is necessary to suppose some kind of semantic bridge from our sense of goodness to this higher sense, but the very notion of such a bridge might be challenged. It is reasonable enough to see how analogical development might allow for words to be used in different ways. Indeed, the semantic evolution of any given term ' $x$ ' may go a long way, and permit its application to things which at first sight seem to be 'hardly $\mathrm{x}$ at all'. We come to see that they are 'in an extended sense' $\mathrm{x}$. However, when the extension proceeds so far as to turn full circle and directly oppose its own starting point we seem to find ourselves in an absurdity - a sort of semantic version of sawing off the branch you are sitting on. But that is what seems to be happening here. For it is being suggested that the higher concept of good is so much further developed than our own, that things are by its lights 'good' which we would call 'evil'. McTaggart expresses robustly what will be the contemptuous reaction of many people to that suggestion: 'There is no judgement about the good of whose truth we are

\footnotetext{
${ }^{8}$ See also McTaggart: 'why should the word good be used in two senses absolutely opposed to one another? The senses are not merely different.... For what is called good in God would be called wicked in men.' (1906, pp. 213-4)
} 
more certain than the judgement that what is painful or sinful cannot be perfectly good. If we distrust this judgement, we have no reason to put any trust in any judgement of good or evil." (McTaggart 1906, p.209)

The problem with this line of complaint lies in its assumed extensional (or referential) theory of meaning. The analogical development or augmentation of language requires a certain overlap of meaning, but having some point of meaning in common need not imply having any extension or reference class in common. Reflecting more deeply on the meaning of a word ' $\mathrm{x}$ ', I may come to conclude that none of the instances or examples standardly given are truly or genuinely $\mathrm{x}$.

An illustration may help here. Asked about the meaning or nature of free will many people naturally look to the idea of libertarian choice, the thought that our decisions are not irrevocably fixed by any prior factors. But there is a familiar line of consideration which may lead this initial concept to develop. For we may reflect that a free choice is one for which we are responsible, an intelligible act done for reasons. But where there are no prior factors at all to move us, whatever happens begins to look like caprice or randomness, and we may end up concluding (for example, with Descartes ${ }^{9}$ ) that such libertarian indifference is in fact the very antithesis of freedom. Now, the issue here is not whether or not we endorse this precise line of argument, but simply that we find it intelligible. On a purely extensional theory our initial examples would fix the meaning of the term 'free will' and render such an evolution impossible. But in fact our understanding is intensional, and the cases from which we set out serve merely as illustrative starting points. For this reason, as our understanding evolves, we may change our illustrations and even come to use ones directly contrary to those from which we started. The difference between speaking about the feature or property that makes us group together various objects as all belonging to a given type and using a term as nothing more than the name of such a set, is that in the former but not the latter case there remains more that we might come to discover about the type in question. But then we cannot exclude the possibility that further examination might show that we were mistaken about any of the examples we first used.

The first half of Mill's objection fails, then - to say that God is good in some higher, but unknown sense, is not simply to open the door to anything and everything. But perhaps there is merit in the second half of Mill's worry. For even if we allow that there is a rather mysterious 'higher' sense of the notion, if God works with this 'higher' standard of evil, it rather seems that he simply does not care about evil in the 'lower' sense. And if he does not care about how we really feel, why should we care about him? That is to say, why should we think him any sort of being that can legitimately command our love and respect?

In Mill's expertly rhetorical hands the complaint sounds like a principled cry of the ill-treated and marginalised. Yet if we stop to think further on the matter, in the light of the theory being considered, what is being asked for here is really very odd indeed. For it needs to be remembered that to this way of thinking evil is not real, and thus we are asking that God take up a limited and partial view: that he see the world with same blindness and distortion that we do. To bring in an analogy, the case is somewhat like

\footnotetext{
9 'The indifference I feel when there is no reason pushing me in one direction rather than another is the lowest grade of freedom: it is evidence not of any perfection of freedom but rather of a defect in knowledge or a kind of negation' (Descartes 1984-1991 volume II, p.40).
} 
that of a spoiled child who does not get their own way and complains bitterly to his or her parents that it is not fair and they just do not understand. There is no need to deny that inside the child feels sincerely hurt and wronged. Nor need we deny that genuinely loving parents will be empathetic ones who make a real effort to understand how things seem from the child's perspective. But there is something absurd in supposing that they ought to endorse or take up the child's own view.

But perhaps we may put a more generous construal on Mill's complaint here if we understand the issue as one of justice. It may be that, taken as a whole, the universe is in a perfect condition, but that grand fact seems little consolation to any given individual who suffers dreadfully. In this sense, the heart of the objection might be thought to be a stand for the 'rights' of the part against the 'demands' of the whole and, as such, a cousin to those objections in political theory which complain that you cannot purchase the wellbeing of society as a whole at the cost of the suffering of some minority. My anguish may be an integral part of the perfection of the universe yet that fact hardly benefits me. But as with the previous line of complaint, this objection fails properly to get behind the position it is criticising. It is important to remember that the specific theory we are considering here is a holistic answer not a greater good one, and for this reason it is a simple category mistake to contrast the evil suffered by any individual with any wider benefit to the whole. Since the former is an appearance and the later a reality, there is no obstacle to our maintaining that from a wider and truer perspective the individual partakes in the final perfection of the whole every bit as much as does everything else contributory to it. Analogously, in joining any civic association (such as a trade union, political party or other organisation constituted by social contract) we may seem to give up a measure of our own individual agency or autonomy, but we do so because we individually attain a greater power when out lot is merged indissolubly with that of others.

\section{VII}

It is not uncommon for objections to the unreality of evil thesis to take on a distinctly moral or outraged tone. 'How can you possibly say that there is no evil?' runs the complaint. 'That is an utterly wicked thing to say.' Now, of course you cannot disprove a theory by appeal to its ethical implications; the relevant question is not what sort of behaviour or attitudes it might encourage, but whether or not it is true. But still, we might wonder if there is not some foundation to the complaint. Is this really a wicked or immoral view? A view might plausibly be described as immoral if it tends to promote immorality: if for example it furthers cruelty and intolerance or indifference and lack of compassion. Does a belief in the unreality of evil do this? Not to believe in the reality of some evils or pains (e.g. those affecting animals or foreigners) might well do so, but would disbelief in the reality of all evils (including those one seems to suffer oneself) have such an effect? Certainly an argument can be constructed for thinking that it might. Dragons are frightful creatures that cause a lot of damage and distress, but there is no need for us to get rid of them, because they are unreal. Similarly, it might be argued, if evil is merely apparent, why attempt to remove it? Why (it might be challenged) does God want us to rectify certain conditions or to avoid certain ways of behaving - as most theists think that he does - unless it is the case that these things really diminish the value of creation? 
There are two reasons for thinking this challenge mistaken. In the first place, were it the case that God designed the universe as a whole in such a way as to ensure that any errors which we make do not in fact detract from its overall quality, this fact need not be taken to undermine the original motivation for acting in accordance with morality. Unless we are mere consequentialists, acting only to further our 'moral wealth' (that is, aiming only to increase the amount of 'goodness' we have brought about), whatever primary reasons there may be for acting in accordance with morality - for being kind, or truthful, or helpful - would remain intact. Not all reasons for acting resolve down to consequences. To take an analogy, when I write I must do so as accurately as possible. The fact that my publisher uses a copy editor to fix the lapses in my spelling and grammar is a reassurance, but it is in no sense a reason for me not to bother with these things. Similarly, if God has created a world where lions live by catching gazelles, then no doubt it would be mistaken for us to interfere and attempt to change that natural order, but the Gazelles still have a very good reason to avoid the lions. Or to take a third case, there was never any chance for Oedipus to escape his fate - and that is why the story is a tragedy - but we can all agree that he is a morally better figure for trying to do so.

The second sort of answer is rather more speculative and controversial. On the view which we are considering reality is already perfect. Nothing we do could ever change its value. As we shape or influence its arrangements, we may suppose that we have improved it. But that is impossible. If we think that we have made the world better or removed evil from it, all that we can really have done is to have changed our view of it. If we are correct to judge that things are better than they once were, it can only be that we are seeing them more truly - closer to the way in which God does - for to his eyes the world is and always has been perfect. From this it follows that the motivation to remove evil is the same as the motivation to see things more truly. If evil is unreal there is no need to eliminate it. But, there is always good reason to come to a clearer and more accurate view of the world and this, looked at through a pragmatic lens, entails that there is always good reason to eradicate apparent evils. The normativity of ethical command is in effect reducible to the normativity of cognition. ${ }^{10}$

It is absolutely vital that this suggestion not be misunderstood. I am certainly not claiming that in the face of evil we should close our eyes and try as hard as possible to believe that really everything is good. This is where Christian Science goes wrong. Knowledge is a function of what we perceive as much as it is of what we think, and thus to confront the world accurately you will have to change your whole experience, not just what you believe about it. The world in which we live is one that we find in both perception and belief.

Taking on that broader challenge, what (we might ask) is the best way to alter our experience? It is sometimes possible to mould our experience by changing our beliefs or feelings, but an equally - and often more - effective course will be through action. The agency by which we shape our own experience may be practical as well as conceptual. Hands-on action may bring us to a truer experience as much as may intellectual development. (Loving someone, for example, may bring you to understand

\footnotetext{
${ }^{10}$ Since it is apparently possible not to care about morality, but inescapably internal to all cognition to be motivated by truth, this answer has the further unforeseen and advantageous consequence of strengthening the normativity of ethical commands.
} 
them more truly than hating or envying them.) It will likely be objected that this line of argument elides the distinction between moral action and moral perception, for there is surely a world of difference between a change in the world which brings it into line with our presumptions about it and our coming to learn the truth about how things stand in the world. ${ }^{11}$ There is certainly a local or pragmatic contrast to be drawn here, but raised up to a level of metaphysical principle, the separation is contentious and implausible. Any reasonably sophisticated account of value experience will appreciate that there is no easy way of distinguishing between what it brings to us and what we bring to it, for while they are more than just reflections of our feelings, it makes a nonsense of their role as values to suppose that good and evil exist in utter independence of how we engage with or respond to them. At the same time, no plausible metaphysics of morals can cling doggedly to the outmoded creed of a hard and fast distinction between facts and values. While the natural scientist may wish to think of action as something explicable in narrowly physical terms, the social theoretician understands that it is something which takes place in a sphere which is already moral - within the space of perceived reasons. Whether we work with our minds or with our hands we change the form of our experience, and we may ask whether what we have done has made it truer or more false, that is to say, closer or further away from the divine view.

\section{VIII}

I conclude with a note of limitation. I have sketched out reasons for thinking that, contrary to received opinion, denial of the reality of evil might serve as an effective solution to the problem of evil. However, an outline solution is not a full answer and, as with any other response, a great deal of work remains to be done in order to ascertain whether this schematic solution could really be turned into a fleshed out and effective theodicy, and whether that theodicy could claim superiority to its more established rivals. I have not attempted those tasks, but argued only that this research programme has as much rationale to be pursued as others currently 'on the market'.

Open Access This article is distributed under the terms of the Creative Commons Attribution 4.0 International License (http://creativecommons.org/licenses/by/4.0/), which permits unrestricted use, distribution, and reproduction in any medium, provided you give appropriate credit to the original author(s) and the source, provide a link to the Creative Commons license, and indicate if changes were made.

\section{References}

Calder, T. C. (2007). Is the privation theory of evil dead? American Philosophical Quarterly, 44(4), 371-381. Dancy, J. (2004). Ethics without principles. Oxford University Press.

Davies, B. (2006). The reality of God and the problem of evil. Continuum.

Descartes, R. (1984-1991). The philosophical writings of Descartes. Cottingham, Stoothof and Murdoch (eds). Cambridge University Press.

Eddy, M. B. (1934). Science and health with key to the Scriptures. Christian Science Publishing Society, authorized edition.

\footnotetext{
${ }^{11}$ This contrast is sometimes given the name 'direction of fit' by its advocates.
} 
Geach, P.T. (1972). Logic matters. Basil Blackwell

Kane, G. S. (1975). The concept of divine goodness and the problem of evil. Religious Studies, 11(1), 49-71. Kripkie, S. (1980). Naming and necessity. Blackwell.

Mander, W.J. (2016). Idealist ethics. Oxford University Press

Mansel, H. L. (1867) The limits of religious thought. John Murray, fifth edition.

McTaggart, J. M. E. (1906). Some Dogmas of religion. E. Arnold.

McTaggart, J. M. E. (1921-7). The nature of existence. Cambridge University Press

Mill, J. S. (1878). Examination of the philosophy of William Hamilton. Longmans, Green, Reader and Dyer, fifth edition.

Moore, G. E. (1903). Principia ethica. Cambridge University Press.

Taylor, C. (1976). Responsibility for self. In Amelie Oksenberg Rorty (ed.), The identities of persons. University of California Press, 281-99. 